\title{
The Experiences and Identity Structures of Teacher-Researcher Hybrid Professionals in a Primary School Mathematics Context
}

\author{
James Anthony Russo ${ }^{1 *}$ \\ ${ }^{1}$ Monash University, AUSTRALIA
}

Received 19 November 2019 • Accepted 5 April 2020

\begin{abstract}
There is frequently a substantial disconnect reported between educational research and classroom practice. It has been proposed that individuals operating at the intersection of research and practice can potentially strengthen the relationship between the two communities through transcending institutional boundaries. The current study involved semi-structured interviews with three such 'hybrid professionals', who were all currently working as teachers in Australian primary schools and had completed PhDs in mathematics education. The purpose of the interviews was to gain insight into their experiences, and associated professional identity structures. Thematic analysis revealed that all participants were motivated to pursue higher-degree research to enhance their practice through the opportunity to specialise and work with an expert in their field. Consequently, rather than the proposed disconnect, there was evidence that at least some researchers within primary mathematics education were viewed as exemplifying expert practice. By contrast, participant professional identity structures did not converge, but remained idiosyncratic. In particular, participants varied in relation to the complexity of their researcher identity when in the classroom teacher role. Several possible directions for future research are outlined.
\end{abstract}

Keywords: mathematics education, primary education, professional development, professional identity, research and practice

\section{INTRODUCTION}

Educational research and classroom practice are frequently disconnected from each other (Broekkamp \& van Hout-Wolters, 2007). Individuals who are able to straddle both academic institutions and schools are potentially uniquely positioned to strengthen relationships between the two communities (FarleyRipple, May, Karpyn, Tilley, \& McDonough, 2018). Such individuals may include those with academic research experience or higher degree research qualifications working within schools; school-based (teacher-researcher) hybrid professionals. The current study involved semistructured interviews with three such school-based hybrid professionals based in Australian primary schools, with the purpose being to gain insight into their experiences, and associated professional identity structures. Research questions were:
1) How can the professional identity structures of school-based hybrid professionals be characterised and interpreted?

2) How can the professional choices and professional journeys of school-based hybrid professionals be best described and understood?

\section{The Research-practice Divide and the Hybrid Professional}

In a similar manner to the expectation that classrooms should be student-centred, it can be argued that academic research within education should aim to be teacher-centred. This conception of educational research was put forward by Dagenais et al. (2012), when they contended that such research should be focused on "accumulating well-established knowledge with practical relevance to provide an action base so that teachers can improve the quality of teaching and, consequently, the quality of learning" (p. 285). 


\section{Contribution to the literature}

- The study involved interviews with three teachers with involvement in institutional research. These participants were described as school-based (teacher-researcher) hybrid professionals. This is the first known study to focus on such individuals, a potentially important group for helping to bridge the research-practice divide.

- Teacher motives for pursuing higher degree research in mathematics education have not been previously explored in the literature. The study revealed that generalist primary teachers pursued research degrees primarily to become better teachers through developing more specialised knowledge.

- Research in mathematics education looking at teacher identity has tended to focus on single professional identity structures (i.e., self as teacher). The study used the Professional Identity Structures framework to explore the dual teacher and researcher professional roles occupied by study participants.

However, there is typically a substantial disconnect between educational research and classroom practice (Broekkamp \& van Hout-Wolters, 2007). Cordingley (2008) attributed this disconnect to the fact that research findings are generally not presented in a style or form that is conducive to engaging teachers. Williams and Coles (2007) presented three additional barriers to teacher engagement with research, including: lack of time, lack of specialised skills and knowledge to evaluate research effectively, and lack of access to research. This disconnect seems problematic, particularly if one agrees with Dagenais et al.'s (2012) view of the purpose of academic research; that is, that it should be focussed primarily on informing practice.

It remains an open question, however, as to how this research-practice divide can be effectively bridged. Should the focus be on changing the institutions; for example, supporting school systems to provide designated time for teachers to engage with academic research? Should the focus be on supporting individuals to transcend institutions; for example, through encouraging individuals to adopt roles that place them at the interface of schools and universities? In support of the latter view, it has been argued that individuals operating at the intersection of research and practice can be conceived of as potentially strengthening the relationship between the two communities through their capacity to transcend institutional boundaries (FarleyRipple et al., 2018; Neal, Neal, Kornbluh, Mills, \& Lawler, 2015). Farley-Ripple et al. (2018) noted that such individuals, who can be described as "research-brokers", may be located within a research community (e.g., university), a practitioner community (e.g., school), or a "third-space" in between research and practice (p. 7).

The broad church of Farley-Ripple et al's (2018) research brokers may include individuals who strive to maintain contemporary, regular connections with the classroom whilst working within universities, as well as individuals with academic research experience or higher degree research qualifications working within schools. The focus for the current paper will be on this latter group, who will be referred to as school-based (teacherresearcher) hybrid professionals. There have been many studies in mathematics education that have construed teachers as researchers (e.g., Adler, 1997; Huillet, 2011; Huillet, Adler \& Berger, 2011); however such studies have tended to focus on the teaching endeavour as action research, with highly-localised research aimed at directly impacting a teacher's own personal practice or practices within their school. The hybrid professional, by contrast, has had direct experience undertaking formal research, where the objectives include explicitly contributing to more universal, abstracted knowledgebuilding. They therefore offer a potentially singular perspective on the relationship between classroom practice as manifest in schools and academic research produced through universities.

Although there does not appear to be any previous attempt in the literature to directly examine whether school-based hybrid professionals can bridge the research-practice divide, there is some indirect evidence that school leadership might benefit from having such individuals as part of their school communities. For instance, most principals tend to not access original research directly; rather, it is those principals with connections to outside sources, which may include university faculty staff, who are both most likely to access research, and, at least in some instances, use research to inform decision-making (Hubbard, 2010). This could be interpreted to mean that having a hybrid professional in a school should not only enhance a principal's access to research, but their capacity or willingness to translate research findings into actionable policy. The contention is that the hybrid professional can act as a potential 'research broker' within the principal's professional network, with the capacity to create a virtuous cycle. Initially, the presence of the hybrid professional within the principal's network may push leadership further towards valuing and using research. This has the effect of reducing the research-practice gap and in turn enhancing the capacity of the hybrid professional to bridge this smaller gap effectively; for example, through providing them with the requisite authority within the school environment to implement innovative pedagogical approaches consistent with best practice. The success of the hybrid professional in 
bridging this research-practice gap may then lead the principal to see research as ever more relevant and usable, pushing the school even further towards embracing research, and thereby further reducing the research-practice gap.

\section{Professional Identities and the Hybrid Professional}

Before proceeding, it should be noted that whilst there has been considerable research on the construct of professional identity within mathematics education, the field has been critiqued in part for key terms being insufficiently defined and specified (Darragh, 2016). Consequently, it is important to clarify who is in scope to be categorised as a school-based (teacher-researcher) hybrid professional, particularly in the context of examining such individuals' professional identities, given that it can be argued that "all teachers are researchers" (Nair, 2007, p. 31). A school-based hybrid professional is viewed as someone who has been formally indoctrinated into a university setting as a researcher (i.e., has been awarded a PhD), and yet remains actively engaged in a classroom and/or leadership role in a school. Although not currently employed as university researchers, their $\mathrm{PhD}$ effectively functions as a "passport" into academia (Hall, 2019, p. 159). Moreover, to ensure that their researcher identity remains active and has a performative component (Darragh, 2016), only those individuals who had recently attended an education research conference were considered in the scope of the study. We might continue the passport metaphor by characterising school-based hybrid professionals as dual citizens, currently residing in one country (School), but with the freedom to come and go (and even relocate) to a neighbouring country (University) as they please.

One factor worthy of examination is how schoolbased hybrid professionals formulate their professional identities, given their possession of multi-faceted, and even dual, professional roles. Indeed, it has been put forward in the research literature that occupying multiple professional roles has implications for one's professional identity formation, which in turn has implications for one's psychological well-being. In particular, it has been suggested that multiple work identities may threaten one's authenticity, both intrapersonally and socially (Caza, Moss \& Vough, 2017). From an intrapersonal perspective, the need to behave differently in different roles or contexts can lead to a fragmentation of self and an identity crisis of sorts, as the notion of a true authentic self loses meaning (Gergen, 1991). From a social perspective, being in multiple roles may lead to others struggling to understand and categorise you; denying you a socially constructed label that allows you to parsimoniously communicate 'who you are' in a professional sense.

It may be, however, that possessing multiple professional identities can actually enhance authenticity
(Caza at al., 2017). Identity theorists have argued that an individual's identity is necessarily complex, and straddles multiple selves (Burke \& Stets, 2009), and that people feel bound to enact this complexity at work (Ramarajan, 2014). Therefore, the constraints of being in one role and trying to enact a single identity may actually lead to feelings of inauthenticity, because the limitations of this role may not allow individuals to express all aspects of themselves. Through adopting multiple roles, individuals are afforded a wider range of action and expression, which allows them to more authentically act out their complex identities (Caza et al., 2017). Consequently, whether being in a hybrid role triggers a crisis of authenticity or actually enables one to be more authentic depends in part on whether one attempts to define their identity (or at least their professional identity) as singular and unchanging, or as multi-faceted and evolving.

Roccas and Brewer (2002) define social identity complexity as "the degree to which individuals view their multiple identities as similar in terms of prototypic characteristics and/or overlapping in terms of in-group members" (p. 16). The more complex identities are when one holds multiple professional roles in mind simultaneously - that is, rather than identifying with only one role, or moving discretely between roles at different periods, the individual identifies with both roles across situations (Caza \& Creary, 2016).

Caza and Creary (2016) presented a framework for describing the identity structures of individuals who simultaneously hold multiple professional roles. They presented five identity structures that differ in their level of cognitive complexity (see Table 1). For instance, it is postulated that an individual who primarily identifies as a classroom teacher and only peripherally as a researcher (dominance), will possess a less complex identity structure compared with the individual who constructs one holistic identity as a teacher-researcher that encompasses both their role as a teacher and researcher (holism). Similarly, a school-based hybrid professional who actively seeks to co-activate their identities, experiencing themselves as teacher and researcher simultaneously whilst in either role (augmentation), will have a more complex identity structure than someone who seeks to activate one identity at any one time (compartmentalisation), embracing the teacher identity in some contexts and the researcher identity in other contexts.

Adopting the more complex identities of holism and augmentation might be challenging for school-based hybrid professionals. Indeed, there does appear to be some evidence that when individuals within mathematics education have reflected on the experience of holding multiple professional roles simultaneously (specifically the roles of teacher and researcher), they have tended to compartmentalise their identity 
Table 1. Professional identity structures (adapted from Caza \& Creary, 2016, p. 26)

\begin{tabular}{lll}
\hline $\begin{array}{l}\text { Identity structure } \\
\text { Dominance }\end{array}$ & Complexity & Description \\
Low & Low & $\begin{array}{l}\text { Individuals define themselves at the intersection of the two professional identities } \\
\text { Individuals define themselves by one primary professional identity to which others are } \\
\text { subordinate }\end{array}$ \\
Holism & High & $\begin{array}{l}\text { Individuals define themselves in multiple professional roles, but in one role at any given time } \\
\text { (i.e., identity activation is context-specific) } \\
\text { Individuals define themselves with one holistic professional identity which encompasses all } \\
\text { others } \\
\text { Individuals define themselves with multiple professional identities that are co-activated, and } \\
\text { complement, extend and enhance one another. }\end{array}$ \\
\hline
\end{tabular}

structures, or allow one identity structure to dominate the other (Russo, 2019; Tabach, 2006).

For instance, Tabach (2006) undertook a selfexamination of her role as a teacher-researcher, as her own secondary mathematics classroom provided the context for, and content of, her PhD inquiry. She identified several conflicts and potential synergies between occupying both roles simultaneously. Most of the dilemmas she described arose from her commitment to the needs of the students in her role as teacher, and her commitment to investigating her research question in her role as researcher. In order to minimise conflict, she frequently attempted to compartmentalise her roles: when she was in her classroom with her students, she was a teacher; when she was reflecting on the lesson and deciding on the contents of what to teach, she was a researcher. In fact, during her concluding remarks, Tabach (2006) explicitly states: "in the classroom, the teacher must act like a teacher, keeping the researcher's voice silent" (p. 239). However, she did note that occupying one role may enhance the other; specifically, that being a researcher might make a teacher more reflective and that being a teacher might broaden one's perspective on research.

By contrast, Russo (2019) used a journaling process to systematically reflect on his experience of teaching with challenging mathematical tasks in a primary school context as part of his PhD project. In a similar manner to Tabach (2006), he discussed the conflict generated through simultaneously occupying a teacher and researcher role. Specifically, he noted time management challenges and the need for consistency across classes, particularly the requirement to implement the lesson structure protocol as designed, interrupted the natural flow of the lesson. Rather than pursue emerging issues that were of particular interest to students, or address important student misconceptions as they arose, he felt constrained to follow a pre-designated structure. In contrast to Tabach, who was able to effectively compartmentalise her teacher and researcher identities, it seemed Russo's identity as researcher was dominant throughout his experience.

Part of the purpose of the current study will be to examine whether the three school-based hybrid professional participants also tended to compartmentalise their identities, or allowed one structure to become dominant, or whether their identity structures are better described by one of the other categories outlined by Caza and Creary (2016).

Finally, there remains the possibility that, rather than denoting multiple meaningful identities in any permanent sense, being a school-based hybrid professional actually characterises a transitory state, as a researcher moves towards classroom teaching, or perhaps more commonly, as a teacher moves towards research. For instance, Tabach (2006) described her own professional journey from a teacher, to a teacher involved in research, to a researcher-teacher; whilst her increasingly prolific research output over the last decade suggests that she has perhaps completed her transition to the role of 'researcher'. Ostensibly, this characterisation of the hybrid professional as a transitory state challenges the notion that there is value in even studying such a phenomenon. Consequently, the extent to which participants appeared to be transitioning between teaching and researcher roles will be examined.

\section{The Current Study}

This study contributes to scholarly research in this field through providing a lens to better understand the experience of the school-based (teacher-researcher) hybrid professional. Specifically, interviews were undertaken with three individuals currently employed in Australian primary school settings who have achieved a PhD in primary mathematics education. The primary aim of this study was to examine the apparent professional identity structures of the three participants, and to attempt to map these structures onto the framework put forward by Caza and Creary (2016):

1) How can the professional identity structures of school-based hybrid professionals be characterised and interpreted?

It should be noted that all three school-based hybrid professionals began their careers as generalist primary teachers. Therefore, their secondary identities as mathematics education researchers were 'acquired' (at least for the purposes of our framing) through completing their PhD. However, it is clear that the act of enrolling in further study could also be conceptualised through a teacher identity lens. 
Indeed, there is precedent within mathematics education that undertaking further study and extended professional learning can help shape teacher identity in a positive manner. Graven (2003) presented the vignette of Ivan, a primary school mathematics and science teacher who participated in a two year in-service education and training programme. Targeted at generalist teachers, the programme was intended to support these educators develop the skills and knowledge to become "professional, competent mathematics teachers" (p. 28). Graven's analysis revealed that participation in the programme helped to strengthen Ivan's identification as a mathematics teacher, re-engage him in the teaching profession, and provided him with some status as expert. In addition, Ivan began to proactively participate with a broader community of fellow mathematics teachers, and regularly shared information within his school to support the instruction of his (now) less expert colleagues.

Similarly, Hodgen and Askew (2007) explored the case study of Ursula, another generalist primary teacher who operated in a South African context. The authors documented Ursula's journey and professional identity evolution following an intensive and sustained professional learning experience (one day a fortnight for three years). Through this experience, Hodgen and Askew reported how Ursula was able to re-connect with mathematics as a discipline following some negative personal experience with the subject in secondary school, embrace the mantle of 'specialist', and reimagine what it meant to be a teacher of mathematics.

In addition to intensive in-service training programmes, the decision to pursue further university education specifically appears to have implications for teacher identity. Nasser and Fresko (2003) examined the motives of 124 Israeli in-service teachers (in earlychildhood, primary education and special education settings) for returning to university to pursue their bachelor degree in education. It was found that the primary impact of further study was to increase teachers' commitment to, and interest in, the teaching profession.

Interestingly, none of the aforementioned studies examined the impact of choosing to undertake 'pure' research degrees (e.g., $\mathrm{PhD}$ ) on a generalist teacher's professional identity. Consequently, a secondary aim of this study is to examine study participants' motives for enrolling in a PhD programme in the first instance, and how this impacted their professional identities as teachers. This will be explored through asking participants to provide some personal background, and elaborating on how they came to pursue a higherresearch degree whilst practising as a primary school teacher:
2) How can the professional choices and professional journeys of school-based hybrid professionals be best described and understood?

\section{INTRODUCTION}

Semi-structured, narrative interviews were undertaken with three school-based hybrid professionals: Alice, Ivy, and Belle. The purpose of these interviews was to understand the nature of this role, and its impact on their professional identity formation. Participants were invited to discuss their own personal experiences, as well as share their perspectives on the hybrid-professional role in a more general sense.

\section{Defining a Hybrid Professional}

For the purposes of this study, a school-based hybrid professional was defined as an individual who:

- Is currently employed in an Australian primary school setting;

- Has completed a PhD (in primary mathematics education);

- Has attended at least one mathematics education research conference in the past two years.

\section{Study Participants}

All three school-based hybrid professional participants had at least 10 years classroom teaching experience in an Australian primary school, and had their PhDs conferred in the past decade. All had attended at least three education research conferences during their careers, and had contributed at least two research papers. Two participants (Ivy, Belle) were currently employed full-time in a school setting with full classroom teaching responsibilities. Whilst Belle was currently the numeracy coordinator at her school, Ivy was in this role until recently for several years. The other participant (Alice) was currently employed part-time in a primary school setting as a mathematics specialist $(0.6$ FTE), and worked part-time as an educational consultant. This specialist role involved Alice modelling lessons, mentoring classroom teachers, working with groups of students identified as having particular learning needs, and overseeing the school mathematics programme (e.g., monitoring data).

Note that, in addition to pseudonyms being used throughout to describe the three study participants, it was decided to not present a detailed profile of each participant due to concerns that this information could be potentially used to ascertain the identity of these individuals, undermining their confidentiality. This is a direct consequence of the fact that the pool of individuals fitting the definition of a 'hybrid professional' used in this project is small and distinctive in most Australian cities. 


\section{Procedure}

Interviews took place at a location outside of the individual's work environment. They were semistructured in nature and lasted at least 45 minutes (Alice, 47 minutes; Ivy, 48 minutes; Belle, 105 minutes). Interviews were audio-recorded and later transcribed verbatim. A list of topics covered included:

- Background of individual, their journey into classroom teaching and research

- Describing their current role(s)

- Positive and negative aspects of their role(s)

- Constraints and enablers in their role(s)

- Connections between research and practice in their role(s)

- Value of having 'hybrid professionals' working in schools

- Career paths for hybrid professionals

- Support for hybrid professionals in their dual roles

\section{Analytical Approach}

Interview data was analysed thematically, and combined "theoretical thematic analysis" with "inductive thematic analysis" (Braun \& Clarke, 2006, p. 84). More specifically, the first research question, focussed on examining the identity structures of participants as hybrid professionals, was analysed theoretically, as participant responses were interpreted through the lens of Caza and Creary's (2016) framework, detailed in Table 1. The second research question, focussed on describing the world of the hybrid professional, was exploratory and involved inductive analysis.

Both thematic analyses approximately followed the six stages put forward by Braun and Clarke (2006); that is, 1) familiarisation with the data, 2) generating initial codes, 3) searching for themes, 4) reviewing themes, 5) defining and naming themes, and, finally, 6) producing the report. However, in line with the authors' recommendations, this was a recursive, rather than linear process. For example, the theoretical thematic analysis to address the first research question initially involved a targeted approach, whereby the interview transcripts were specifically read and annotated for content relating to professional identity themes. However, once these themes were collated and crosschecked against the Caza and Creary (2016) framework, the transcriptions were re-read, to ensure that the proposed analysis appropriately captured the participant's description. In some cases, further refinements and modifications were made to the proposed analysis in response to this revisiting of the primary data.

\section{RESULTS}

The analysis section is structured around the two research questions. In order to present a more cohesive narrative reflecting the chronology of events in the lives of the three participants, the second research question is addressed first. Themes that arise in relation to each question are presented as sub-headings. Participant quotations were used selectively to illustrate particular themes, and to add thickness and richness to their description.

\section{How can the Professional Choices and Professional Journeys of School-based Hybrid Professionals be Best Described and Understood?}

The themes that emerged when considering the professional choices and journeys of the hybrid professional participants included: greater specialisation as progression; and pursuing research as a professional learning journey.

\section{Greater specialisation as progression}

The three study participants all appeared to make a conscious decision to sidestep pursuing promotion within a conventional hierarchical structure in favour of a more idiosyncratic, personally-meaningful pathway. For each participant, having completed a Masters course in numeracy or mathematics aimed at primary school teachers, the decision to undertake a $\mathrm{PhD}$ whilst working in schools allowed them to pursue further specialisation in mathematics as a content focus. The resolution to enhance their content and pedagogical knowledge of mathematics was valued in part because it allowed participants to remain connected to the actual teaching of students. By contrast, a leadership pathway, seemingly a viable alternative for all three participants, was rejected precisely because it was viewed as taking them out of the classroom.

Alice noted that when she returned from maternity leave, she made a conscious decision to pursue a specialisation pathway over attempting to become a principal:

I was a classroom teacher, and I'd held a lot of positions of leadership. I stopped and left to have children. When I returned... I decided I have to actually look at what I'm going to do, because I don't want to be a principalwhat am I going to do besides that? I decided study. I've always liked maths, that's probably been my favourite subject. Having said that though, I just wanted an area where I could specialise in.

A significant motivation for pursuing greater specialisation was it enabled all three participants to stay connected to students whilst deepening their professional knowledge. Although Alice was currently in a specialist role meaning she was not responsible for a 
grade, she still spent the majority of her three days a week in schools working directly with students, either in small focussed teaching groups, or through mentoring arrangements, which frequently involved teamteaching. By contrast, both Ivy and Belle had been, or were currently in, numeracy coordinator positions, however indicated that their priority was to ensure they still taught their own class. Ivy discussed how her rejection of this more conventional was often perplexing to others:

\section{I think, too, that a lot of people don't understand that I don't want to progress in a university. In fact, I don't want to progress - if you call it progressing - in a school, I don't want to do leadership, I'm not looking for the next level.}

Likewise, after spending some time in a university role teaching pre-service teachers and then returning to classroom teaching, Belle was clear that her priority was to remain in the classroom working with children:

I don't want to be a Principal and I don't want to be out of the classroom. So I don't want to be a Level 2 Maths Coordinator who's out of the classroom. If I wanted to do that, that's working with adults, I'd be in the University sector.

Indeed, Belle's initial motive for moving out of the classroom to pursue higher degree qualifications, and eventually a PhD, was to get to know 'good teaching'. She ascertained that she had reached a certain level of competence in her practice, and was ready to absorb new knowledge and experiment with alternative pedagogical approaches:

I was at that point where I had enough to start... but you want something more. You want to really know good teaching, you're ready for that. Going and doing that course was my way of going, 'I want to find out about good practice.'

The idea that school-based hybrid professionals associate their personal engagement in university courses, including higher-degree research courses, as moving them further towards enacting good teaching practice connects to our next theme: Pursuing research as a professional learning journey.

\section{Pursuing research as a professional learning journey}

This theme builds on the theme of greater specialisation as progression. However, rather than describing their over-arching career direction and motives for pursuing greater specialisation, it refers to the outcomes identified by school-based hybrid professionals resulting from the decision to pursue higher degree research, as well as the specific mechanisms that led to these particular outcomes.
All three participants were unequivocal in contending that completing their PhDs had made them more effective teachers. As Alice stated:

It's totally changed the way I teach, it's totally changed the messages I'm sending to my teachers... Certainly if I look back five years... I think I was a good teacher then, but I think I see things very differently now.

Similarly, when commenting on whether she believes she is a more effective teacher than before she did her $\mathrm{PhD}$, and spent some time away from the classroom to focus on pre-service teacher education, Belle noted:

I am a much better teacher than I was the first time around... By about a million percent!... Yeah. I don't think I could be the type of teacher that I am now without the experiences that I had in the University sector.

Ivy concurred that completing a PhD had enhanced her teaching practice, emphasising that her academic research pursuits had sharpened her critical orientation:

I think it's changed the way that I look at things, so I now look for - okay, there's an idea, where is the research? Can I read some of that?... But before I studied, I probably would have just accepted things from leaders or whatever.

The question arises: what were the mechanisms that led to these changes in practice? Again, it was interesting to note the concurrence in responses amongst the three participants, who all emphasised the importance of their relationships with their respective PhD supervisors, each of whom possessed content and pedagogical knowledge that was perceived as both outstanding and transformative. As noted by Alice, her PhD supervisor was a critical source of knowledge throughout her project:

I think I was lucky, because the supervisor I had. So, I would say I learnt as much from him as I did from actually the readings and all of that sort of stuff... Every time I'm doing something, at the end of the day I need it to affect my school... He [my supervisor] was terrific with that.

Beyond directly impacting her content knowledge, Alice's relationship with her supervisor enhanced her pedagogy, as she viewed him as an exemplary role model. Through internalising this model of teaching, she determined that she had become more effective in her mentoring of other teachers. In particular, she noted that stepping away from 'spoon-feeding' and embracing a growth mindset seemed particularly important for changing the way she approached her mentoring role:

I also actually learnt about how to be a teacher from watching how he did it with me... I thought he was pretty tough at times, and could have spoon-fed me 
more... and as I went along in the process, I realised actually that's probably what I do poorly... my supervisor actually had a massive effect on the way I see myself as a teacher working with kids, or other teachers.

It is interesting to note that Alice's level of professional respect for her would-be PhD supervisor prior to enrolling in her $\mathrm{PhD}$, and her perception that she could learn substantially from this person in a practical sense, was a significant factor in her decision to pursue her research project to begin with:

I respected that he was still very much in schools, and that's a big thing. Because, it's all very well for people to talk to you, but when you look at them and you think, wow when was the last time you were in a school? It does affect how you take their advice.

For Belle, after having the opportunity to pursue a Masters course connected to a professional learningoriented research project headed by a team of academics she had come to respect immensely, she decided that the chance to continue to work with this group of individuals was effectively too good to let pass:

I had the opportunity that I could do my PhD with Prof X. at Uni X. with that team. Part of me was like, this is a series of events that exists now, so yes, it might be better to delay it for five years, but we don't know that that group of people will be there in five years.

Similarly, and again emphasising the value participants placed on being able to work with whom they considered expert practitioners, Ivy noted that part of her motivation for doing a $\mathrm{PhD}$ initially was to continue to work directly with the mathematics educators she had engaged with during a research project her school was involved in:

It was just so engaging and it was with such amazing people. People running it were just so inspiring and I could see the change in the kids straightaway. So when it finished I just wanted more, which is why I then went on to do the study.

However, Ivy also credited the wide range of professional reading she was able to do through pursuing her $\mathrm{PhD}$ as being responsible for transforming her practice:

But the opportunity to read all that research, teachers just don't have that opportunity... So that to me changed me a lot... my PhD took me in so many different directions that I had to read really broadly.

Consequently, it seems that a large part of the three participants' motivation for pursuing a PhD was to continue to enhance their professional practice through working with individuals who they had identified as expert practitioners, who would function as their $\mathrm{PhD}$ supervisors. All three participants also concluded that their professional practice had in fact been transformed through undertaking their $\mathrm{PhD}$ project, and all attributed this transformation in substantial part to the opportunity to work closely with these expert practitioners. Given these clear practical gains for their own classroom practice and their capacity to guide the practice of others, it is interesting to consider whether our so-called hybrid professionals predominantly construe their researcher identities in purely instrumental terms, or whether they have instead internalised and integrated their 'research self' into their professional identity. Such considerations connect to our next research question examining professional identity structure.

\section{How can the Professional Identity Structures of School-based Hybrid Professionals be Characterised and Interpreted?}

The professional identity structures of each of the three participants were examined in relation to the framework developed by Caza and Creary (2016) for interpreting how individuals, such as our school-based hybrid professional participants, make sense of their multiple professional identities. It needs to be noted that the two professional identities being considered are 'self as teacher (in a school setting)' and 'self as researcher'. Each of the three participants will be considered separately. For Alice and Ivy, rather than conclude that their identity structure can be clearly categorised into one of the five multiple identity structures offered by Caza and Creary, it will instead be proposed that their identity structures are best understood as encompassing multiple identity categories.

\section{Alice: Dominant or a single identity?}

From Alice's perspective, engaging with the university sector and doing a PhD was primarily about enhancing her knowledge as an educator, and, to a lesser extent, her legitimacy as a consultant. Her interest in becoming a researcher appeared largely peripheral to these initial central motives, and this aspect of her identity remained almost inert. From this view point, it can be argued that Alice is not appropriately categorised as a hybrid professional at all (at least, not as a teacherresearcher hybrid professional), but rather a teacher and consultant who temporarily engaged with academic research largely for instrumental purposes. This would imply that Alice could not be classified according to Caza \& Creary's (2016) framework, and would instead have a single professional identity, 'self as teacher':

\footnotetext{
My last comment would be, at the university I learnt doing what I did, I still believe it's because of the supervisor I had. I've learnt heaps, invaluable. If you asked me would I do it again? Probably not, because it's
} 
too much work, but it was invaluable to change my teaching.

However, even though Alice did not necessarily have a well-developed identity as a researcher, the acts of accessing, translating and applying research have become infused with her teaching practice. Central to this was the process of incorporating her own $\mathrm{PhD}$ research findings into her teaching and consulting (i.e., her teaching of teachers):

I work with another person who also has a PhD, and we'd already done a lot of the practical professional development days, and they'd been very successful... We already had research behind what we were saying but we embed a lot more of what we studied into it, so that people realise we're not just saying, "Oh it sounds good." We actually have some evidence behind what we're saying.

Consequently, rather than conclude that Alice has a single identity structure ('self as teacher'), we may instead contend that she is indeed a hybrid teacherresearcher, with a dominant teacher identity.

\section{Ivy: Augmentation, Holism or Compartmentalism?}

In contrast to Alice, it would appear that Ivy can be unambiguously described as possessing multiple professional identities. However, although her identity structure appears to be further along the complexity continuum compared with Alice, it is not immediately apparent whether Ivy's identity is most appropriately described as augmentation, holism or compartmentalism.

Early in the interview, there was some evidence that Ivy's identity structure could be described as compartmentalisation, as she distinguished between being in her 'research head' and her 'teaching head':

I feel like I have two heads sometimes. So I've got my teacher head, which is great, very busy and does think about things... and it's a different kind of head to my research head. So I like to be able to use that brain- my research brain-every now and then, when I can. So that research project not long after my PhD really gave me that feeling that I love to do this stuff. I love to teach but I love to research.

Contrasting with this characterisation, later in the interview, Ivy also described the development of an enhanced critical orientation in her teaching role, which she attributed to her prolonged engagement with the research process and the research literature during her $\mathrm{PhD}$. This in turn suggests that she may have been in the process of developing a single professional identity that encompassed both her teaching self and research self, implying that Caza and Creary's (2016) category of holism might best describe her identity structure:
I'm much more critical about - where's the research for this? And what is the basis that we're doing this? And that kind of stuff. I think in my own classroom... I research all the time with the kids. I'm always asking questions of myself about their learning, and then tinkering around with things. So it's a different way of thinking and I think - I don't think you can ever get out of it once you start it.

However, in addition to Ivy experiencing her formal research as shaping her teaching practice, she clearly viewed the relationship as bi-directional; her teaching experiences in the classroom became a potential springboard for further formal research. In a sense, the very act of teaching ignited her identity as a researcher:

I think I am looking for ways to formalise all these research ideas I have about my kids. So you know, there's a million papers in my head. There's probably another research project just in my own classroom... That kind of thing would really interest me... I think it would be fascinating... because imagine looking at one child - or even two or three children's learning over a whole year.

This last quotation implies that, rather than holism that would be characterised by a dissolution of boundaries between her researcher and teacher self, Ivy's identity may be more appropriately described as augmentation. In the case of augmentation, her researcher and teacher identities remained distinct, however were frequently co-activated; being in either one role also brought to mind the other role. Moreover, this co-activation operated synergistically; rather than being a source of conflict, having both roles activated enhanced her capacity to perform both effectively.

Having said this, having her researcher identity continually enacted without having the opportunity to fully actualise it remained a source of frustration for Ivy:

But I'm not attached to a university formally. When would you have the time to do that (formal research)? And I feel like there's other barriers in the way... I think that it's a shame...

\section{Belle: Dominance}

The participant with perhaps the least ambiguity regarding her identity structure was Belle. Although Belle remained keenly interested in academic research, particularly in enacting what she had learnt from research in her classroom, and was actively looking for opportunities to collaborate with academics in her classroom teaching role, her teaching identity remained dominant.

One particular anecdote Belle shared whilst she was working in the university sector is particular revealing. It implies that Belle's professional identity as a classroom 
teacher had remained central, irrespective of the context in which she had been operating:

When I was working as a lecturer, I was at a party, and someone said to me, what do you do? And I said, I'm a Primary teacher, and then I went, but I'm not in the classroom at the moment. And they said, what are you doing? I said, well, I'm lecturing at the University... I thought, I'm in my mid 40's, if I don't go back, I'll never get back... my true skill set is working with little kids, so it's crazy not to be doing it...

It appeared then that spending time away from classroom teaching in a university role helped to clarify Belle's professional identity. Her primary school teaching identity remained alive even when she was several years removed from having any direct classroom teaching responsibilities. However, it is inaccurate to classify Belle as possessing a single professional identity ('self as teacher'), as she still felt a strong desire to meaningfully contribute to academic research, albeit operating from a classroom teacher perspective:

The ideal position is that (classroom-teacher and mathematics learning specialist), plus links to a university. So doing a research project with whoever it might be, so that you've got those links backwards and forwards to the university... You're the person with a Grade, and you're a teacher that they could write with. Because I can write, and think.

\section{DISCUSSION AND CONCLUSION}

There are several issues that emerged from the preceding analysis that warrant consideration. First, given that one of the motives for exploring this topic originally was the acknowledged gap between research and practice in education (Broekkamp \& van HoutWolters, 2007), it seems noteworthy that the major motive for the three study participants to enrol in a $\mathrm{PhD}$ program was specifically to improve their own classroom practice. This implies that, at least within primary school mathematics, education research is not viewed as being disconnected from practice, but rather is construed as driving improvements in practice. More particularly, rather than the belief in the practical relevance of research per se, it was the belief that working directly with specific researchers who would serve as $\mathrm{PhD}$ supervisors would improve participant practice. Moreover, participant reflections indicated that these benefits were actually realised; they did view themselves as becoming more expert classroom practitioners, which they attributed at least in part to their relationships with these specifically chosen supervisors. Indeed, there was substantial overlap in the outcomes associated with pursuing higher research, and those associated with undertaking university course work degrees (Nasser \& Fresko, 2003) and extended professional learning (Graven, 2003; Hodgen \& Askew,
2007); for example, gaining greater pedagogical expertise in mathematics. It is interesting to consider whether these highly pragmatic, practice-based motives for pursuing higher degree research are generalisable beyond the current study, and whether they are particular to primary mathematics education, or also apparent within other education disciplines.

Secondly, it has been suggested that occupying multiple professional roles may generate cognitive conflict, as individuals sense that their professional expertise is diluted, and experience themselves as imposters or lacking mastery (Caza et al., 2017). However, this was not the case for the three participants. On the contrary, one of the primary motives for pursuing research was to become a specialist in a particular subject matter area, as an alternative pathway to leadership. Pursuing a PhD in effect enabled the three participant generalist primary teachers to become relative experts in a particular field. In effect, through the $\mathrm{PhD}$ experience, the participants were able to counter the narrative experienced by primary teachers that they are "jack of all trades but an expert in none" (Russo \& Hopkins, 2019, p. 771). Consequently, findings from this study are consistent with the notion that possessing multiple professional roles can actually enhance authenticity (Caza et al., 2017). However, rather than attribute this enhancement to the opportunity to more fully realise their complex, multi-faceted selves in a work context (Ramarajan, 2014), there was an implication that through enlarging their professional identities to encompass the role of 'researcher', participants were actually pursuing excellence in classroom teaching.

Third, although the Caza and Creary (2016) framework shed light on how individuals configured their identities, it was difficult to unequivocally categorise participants into a defined category in terms of their professional identity complexity. Ivy's responses in particular appeared to straddle multiple categories, and, in different points in the interview, provided evidence for each of the compartmentalisation, holism and augmentation identity structures. By contrast, it appears possible to rank participants in order of their teacher-researcher identity complexity, with Alice having the least developed identity as a researcher, and Ivy the most developed. Interestingly, and in contrast to Tabach's (2006) experience, there was relatively little evidence of participants compartmentalising the two roles. It can be tentatively suggested at this stage that the identity structures for individual school-based, teacherresearcher hybrid professionals remain fairly idiosyncratic, with no clear pattern emerging; although it may be postulated that the more complex identity structures (e.g., holism, augmentation) appear somewhat atypical.

Finally, there was no evidence that the school-based hybrid professionals in the current study were actually individuals transitioning between teaching and research 
roles following completion of their PhDs. Specifically, Ivy and Belle both had several opportunities to work in the tertiary sector, and ultimately decided to remain in classroom teaching roles. Moreover, Alice maintained little interest in pursuing a role in an academic institution. Consequently, the category of 'hybrid professional', at least in terms of how the construct has been defined in the current paper, appears to constitute something more substantial than a temporary, transitory state.

\section{Future Research Directions}

Although limited by both its small-scale design (i.e., three participants, single-point in time) and its exploratory nature, this study has been fruitful in generating potential future research directions. Several of these possible directions are discussed below.

One of the primary benefits of hybrid professionals is likely to be their capacity to bridge the research-practice gap. Future research could seek to examine this issue in its own right. In particular, it could be argued that the extent to which hybrid professionals are able to effectively reduce the research-practice gap is likely to be dependent on a number of factors, some of which are related to the characteristics of the hybrid professionals themselves, and others which are contextual. With regards to their personal characteristics, it could be hypothesised that hybrid professionals will be more effective at bridging the gap between research and practice if they have particular skills, knowledge, dispositions, reputation and networks. With regards to contextual aspects, the hypothesis would be that hybrid professionals will be more effective when contextual factors 'pull' academic research closer to classroom practice, for example: when practice-oriented research questions are pursued within research institutions. Similarly, hybrid professionals will be more effective when contextual factors 'push' classroom practice closer to research, for example: when school leadership value research and are highly supportive of individuals with research expertise.

In addition, future research could also consider connecting the capacity of hybrid professionals to bridge the research-practice gap to the multiple professional identity framework introduced by Caza and Creary (2016), and utilised in the current paper. Specifically, it could be argued that the more complex the professional identity structure formulated by the hybrid professional, the better able they will be to bridge the research-practice gap. For instance, it is postulated that an individual with a dominant identity structure who primarily identifies as a classroom teacher and only peripherally as a researcher, will, all else being equal, be less effective in bridging the research-practice gap than the individual with one holistic identity as a teacher-researcher which encompasses both their role as a teacher and researcher (holism). Moreover, it can be argued that a hybrid professional who actively seeks to co-activate their identities, experiencing themselves as teacher and researcher simultaneously whilst in either role (augmentation), will (again all else being equal) more effectively connect research and practice than someone who compartmentalises their identity, embracing the teacher identity in some contexts and the researcher identity in other contexts. Taking the participants from the current study as an example, we might ask whether Ivy, with her apparently more complex professional identity, is better able to bridge the research-practice divide than Alice.

Finally, and continuing to build on the professional identity literature, it might be worthwhile to examine the similarities and differences between the group of individuals classed in the current study as hybrid professionals and other individuals who can be described as being driven to enact forgone professional identities. For instance, what characteristics do hybrid professionals share with those academics who pursue 'real enactment' of their former professional identity as a classroom teacher through 'job crafting' (Obodaru, 2017); for example, through conceptualising and pursuing a research project which has them teamteaching in a classroom for half-a-day a week? Do academics pursuing 'real enactment' have more in common with hybrid professionals than with other academics pursuing more passive forms of enacting forgone professional identities, such as vicarious enactment (e.g., spending time empathising with classroom teachers)? Are hybrid professionals more jobsatisfied than academics enacting their forgone identity as a teacher, because they are more directly meeting what is likely to be experienced by the latter group as an "unfulfilled value" (Obodaru, 2017, p. 523)?

There is significant interest in strengthening connections between research and practice within the field of education (Farley-Ripple et al., 2018). Given this interest, better understanding the experiences of individuals who straddle these two domains has substantial potential benefit. The current study has attempted to shed some light on the motives and identity structures of one such group; specifically, school-based, teacher-researcher hybrid professionals within the field of primary mathematics education.

\section{REFERENCES}

Adler, J. (1997). Professionalism in process: Mathematics teacher as researcher from a South African perspective. Educational Action Research, 5(1), 87103. https:/ / doi.org/10.1080/09650799700200016

Braun, V., \& Clarke, V. (2006). Using thematic analysis in psychology. Qualitative Research in Psychology, 3(2), 77-101. https://doi.org/10.1191/1478088706qp0 63 oa 
Broekkamp, H., \& van Hout-Wolters, B. (2007). The gap between educational research and practice: A literature review, symposium, and questionnaire. Educational Research and Evaluation, 13(3), 203-220. https:// doi.org/10.1080/13803610701626127

Burke, P. J., \& Stets, J. E. (2009). Identity theory. Oxford University Press. https://doi.org/10.1093/acprof: oso/9780195388275.001.0001

Caza, B. B., Moss, S., \& Vough, H. (2017). From Synchronizing to Harmonizing: The Process of Authenticating Multiple Work Identities. Administrative Science Quarterly, 0001839217733972. https:// doi.org/10.1177/0001839217733972

Caza, B., \& Creary, S. (2016). The construction of professional identity [Electronic version]. Retrieved on 2 February 2018, from Cornell University, SHA School site: http://scholarship.sha.cornell.edu/ articles / 878

Cordingley, P. (2008). Research and evidence-informed practice: focusing on practice and practitioners. Cambridge Journal of Education, 38(1), 37-52. https:/ / doi.org/10.1080/03057640801889964

Dagenais, C., Lysenko, L., Abrami, P. C., Bernard, R. M., Ramde, J., \& Janosz, M. (2012). Use of researchbased information by school practitioners and determinants of use: a review of empirical research. Evidence \& Policy: A Journal of Research, Debate and Practice, 8(3), 285-309. https://doi.org/10.1332/ $174426412 \times 654031$

Darragh, L. (2016). Identity research in mathematics education. Educational Studies in Mathematics, 93(1), 19-33. https:// doi.org/10.1007/s10649-016-9696-5

Farley-Ripple, E., May, H., Karpyn, A., Tilley, K., \& McDonough, K. (2018). Rethinking Connections Between Research and Practice in Education: A Conceptual Framework. Educational Researcher, 0013189X18761042. https://doi.org/10.3102/0013 $189 \times 18761042$

Gergen, K. J. (1991). The saturated self: Dilemmas of identity in contemporary life: Basic books.

Graven, M. (2003). Teacher learning as changing meaning, practice, community, identity and confidence: The story of Ivan. For the Learning of Mathematics, 23(2), 28-36.

Hall, E. (2019). Grasping the nettle of 'doctorateness' for practitioner academics: a framework for thinking critically about curriculum design. Studies in Continuing Education, 41(2), 157-172. https:// doi.org/10.1080/0158037X.2018.1526781

Hodgen, J., \& Askew, M. (2007). Emotion, identity and teacher learning: Becoming a primary mathematics teacher. Oxford Review of Education, 33(4), 469-487. https://doi.org/10.1080/03054980701451090
Hubbard, L. (2010). Research to practice: The case of Boston Public Schools, Education Matters and the Boston Plan for Excellence. In C. E. Coburn \& M. K. Stein (Eds.), Research and practice in education: Building alliances, bridging the divide (pp. 55-72). Lanham, MD: Rowman \& Littlefield.

Huillet, D. (2014). Teacher as Researcher in Mathematics Education. Encyclopedia of Mathematics Education (pp. 582-583): Springer. https://doi.org/10.1007/ 978-94-007-4978-8_148

Huillet, D., Adler, J., \& Berger, M. (2011). Teachers as researchers: Placing mathematics at the core. Education as change, 15(1), 17-32. https:/ / doi.org/10.1080/16823206.2011.580769

Nair, S. (2007). Teachers as researchers: Researchers as teachers? Towards successful educational research. Malaysian Journal of Educators and Education, 22, 2544.

Nasser, F. M., \& Fresko, B. (2003). The contribution of completing degree studies to teachers' professional development in Israel. Educational Studies, 29(2/3), 179-193. https:/ / doi.org/10.1080/03055690303271

Neal, J. W., Neal, Z. P., Kornbluh, M., Mills, K. J., \& Lawlor, J. A. (2015). Brokering the researchpractice gap: A typology. American Journal of Community Psychology, 56(3-4), 422-435. https:// doi.org/10.1007/s10464-015-9745-8

Obodaru, O. (2017). Forgone, but not Forgotten: Toward a Theory of Forgone Professional Identities. Academy of Management Journal, 60(2), 523-553. https:/ / doi.org/10.5465/amj.2013.0432

Ramarajan, L. (2014). Past, present and future research on multiple identities: Toward an intrapersonal network approach. The Academy of Management Annals, 8(1), 589-659. https://doi.org/10.5465/ 19416520.2014.912379

Roccas, S., \& Brewer, M. B. (2002). Social identity complexity. Personality and Social Psychology Review, 6(2), 88-106. https://doi.org/10.1207/S15327957 PSPR0602_01

Russo, J. A. (2019). Walking the Line between Order and Chaos: A Teacher-Researcher's Reflection on Teaching Mathematics with Challenging Tasks in Primary Classrooms. International Journal of Innovation in Science and Mathematics Education (formerly CAL-laborate International), 27(3), 14-24. Retrieved from https://openjournals.library. sydney.edu.au/index.php/CAL/article/view/13 210/12079

Russo, J., \& Hopkins, S. (2019). Teachers' perceptions of students when observing lessons involving challenging tasks. International Journal of Science and Mathematics Education, 17(4), 759-779. https://doi.org/10.1007/s10763-018-9888-9 
Tabach, M. (2006). Research and teaching-Can one person do both? A case study. In J. Novotna, H. Moraova, M. Kratka, \& N. Stehlikova (Eds.), Proceedings of the 30th Conference of the International Group for the Psychology of Mathematics Education (Vol. 5, pp. 233-240): ERIC.
Williams, D., \& Coles, L. (2007). Teachers' approaches to finding and using research evidence: an information literacy perspective. Educational research, 49(2), 185-206. https://doi.org/10.1080/ 00131880701369719

\section{http://www.ejmste.com}

